\title{
Age Is the Only Predictor of Poor Bowel Preparation in the Hospitalized Patient
}

\section{Citation}

McNabb-Baltar, Julia, Alastair Dorreen, Hisham Al Dhahab, Michael Fein, Xin Xiong, Mike O' Byrne, Imene Ait, Myriam Martel, and Alan N. Barkun. 2016. "Age Is the Only Predictor of Poor Bowel Preparation in the Hospitalized Patient." Canadian Journal of Gastroenterology \& Hepatology 2016 (1): 2139264. doi:10.1155/2016/2139264. http:// dx.doi.org/10.1155/2016/2139264.

\section{Published Version}

doi:10.1155/2016/2139264

\section{Permanent link}

http://nrs.harvard.edu/urn-3:HUL.InstRepos:27662114

\section{Terms of Use}

This article was downloaded from Harvard University's DASH repository, and is made available under the terms and conditions applicable to Other Posted Material, as set forth at http:// nrs.harvard.edu/urn-3:HUL.InstRepos:dash.current.terms-of-use\#LAA

\section{Share Your Story}

The Harvard community has made this article openly available.

Please share how this access benefits you. Submit a story.

\section{Accessibility}




\title{
Age Is the Only Predictor of Poor Bowel Preparation in the Hospitalized Patient
}

\author{
Julia McNabb-Baltar, ${ }^{1}$ Alastair Dorreen, ${ }^{2}$ Hisham Al Dhahab, ${ }^{3}$ Michael Fein, ${ }^{2}$ Xin Xiong, \\ Mike O' Byrne, ${ }^{2}$ Imene Ait, ${ }^{2}$ Myriam Martel, ${ }^{2}$ and Alan N. Barkun ${ }^{2}$ \\ ${ }^{1}$ Division of Gastroenterology, Hepatology and Endoscopy, Brigham and Women's Hospital, Harvard Medical School, \\ Boston, MA, USA \\ ${ }^{2}$ Division of Gastroenterology, McGill University, Montreal, QC, Canada \\ ${ }^{3}$ Royal Hospital, Muscat, Oman \\ Correspondence should be addressed to Alan N. Barkun; alan.barkun@muhc.mcgill.ca
}

Received 22 February 2016; Accepted 5 April 2016

Academic Editor: John Marshall

\begin{abstract}
Copyright (C) 2016 Julia McNabb-Baltar et al. This is an open access article distributed under the Creative Commons Attribution License, which permits unrestricted use, distribution, and reproduction in any medium, provided the original work is properly cited.
\end{abstract}

\begin{abstract}
We examine the impact of key variables on the likelihood of inpatient poor bowel preparation for colonoscopy. Records of inpatients that underwent colonoscopy at our institution between January 2010 and December 2011 were retrospectively extracted. Univariable and multivariable logistic regression models were fitted to assess the effect of clinical variables on the odds of poor preparation. Tested predictors included age; gender; use of narcotics; heavy medication burden; comorbidities; history of previous abdominal surgery; neurological disorder; product used for bowel preparation, whether or not the bowel regimen was given as split or standard dose; and time of endoscopy. Overall, 244 patients were assessed including 83 (34.0\%, 95\% CI: 28.1-39.9\%) with poor bowel preparation. Cecal intubation was achieved in $81.1 \%$ of patients (95\% CI: 76.2-86.0\%). When stratified by quality of bowel preparation, cecal intubation was achieved in only $65.9 \%$ (95\% CI: $60.0-71.9 \%$ ) of patients with poor bowel preparation and $89.9 \%$ (95\% CI: 86.1-93.7\%) of patient with good bowel preparation. In multivariate logistic regression analysis, only advancing age was an independent predictor of poor bowel preparation ( $\mathrm{OR}=1.026, \mathrm{CI}: 1.006$ to 1.045 , and $p=0.008$ ). Age is the only independent predictor of poor bowel preparation amongst hospitalized patients.
\end{abstract}

\section{Introduction}

The Multisociety Task Force on Colorectal Cancer recommends a target of $90 \%$ colonoscopy completion rate $[1,2]$, which is essential to meet the diagnostic and therapeutic aims of the procedure. However, the success of a colonoscopy relies on many factors, which include age, comorbidities, location of procedure, bowel preparation [3], and timing of endoscopy [4].

On the matter of bowel preparation, investigators have also examined characteristics associated with an adequate bowel preparation. These include admission status, gender, age, obesity, socioeconomic status, comorbidities, insurance status, number and type of medications, and time of endoscopy, as well as time between preparation and endoscopy [4-12]. Few investigators have assessed these outcomes in the context of hospitalized patients, which represents a higher risk population, where success of the procedure is likely to be more significant than the typical screening colonoscopy performed in the elective setting. Given the limited resources available and the cost of inadequate bowel preparation [13], we examine the impact of patient characteristics on the likelihood of poor bowel preparation at inpatient colonoscopy.

\section{Methods}

2.1. Study Design, Setting, and Participants. The records of inpatients who underwent colonoscopy at our institution between January 1, 2010, and December 31, 2011, were retrospectively extracted from EndoWorks (Olympus, Center Valley, PA). Endoscopists at our institution have a mean annual caseload of 533 colonoscopies between 2013 and 2015. Fellows 
and residents participated in 59\% of cases, all of which were supervised. Six individuals reviewed hospital charts, and $10 \%$ of cases were audited for validation. All data collection and analyses were undertaken following the approval and institutional oversight of the Institutional Review Board for the Protection of Human Subjects.

2.2. Variables. The primary endpoint examined was poor bowel preparation. Patient and demographic information collected included age, gender, race, body mass index, comorbidities (cirrhosis, malignancy, renal impairment, and neurologic disorder), indication for colonoscopy, number of previous colonoscopies, previous abdominal surgery, and time between bowel preparation and start of colonoscopy, as well as time of the day and context (elective, emergent, and urgent) of endoscopy. Baseline comorbidities were determined using the Charlson Comorbidity Index (CCI) and stratified according to four levels: $0,1,2$, and $\geq 3[14,15]$.

Bowel preparation was categorized according to four groups: poor, fair, good, and excellent preparation by the endoscopist. Poor bowel preparation was defined as poor or fair bowel preparation.

2.3. Study Size. The sample size of 500 was chosen to reflect the estimated number of events for the least frequently reported outcome of interest, for example, $23 \%$ incomplete bowel preparation, and the number of variables to be tested [16].

2.4. Statistical Methods. The incidence of poor bowel preparation was assessed. In univariate analyses, quantitative variables were examined as both continuous and categorized variables. The minimum $p$ value approach, as described by Mazumdar and Glassman [17], was used to identify the most significant cut-offs for prediction of the outcome of interest. The most informative format of the variable was then retained for multivariable analyses. Multivariable logistic regression models for prediction of poor bowel preparation were fitted.

To assess multicollinearity between variables and CCI, we assessed the variance inflation factor (VIF) collinearity statistic and the tolerance [18]. Analyses were performed using SPSS (v21.0).

\section{Results}

Overall, 244 charts of patients undergoing colonoscopy during hospitalization were assessed. Of those, 83 (34.0\%, 95\% CI: $28.1-39.9 \%)$ patients had poor bowel preparation. During endoscopic examination, the cecum was reached in 198 patients $(81.1 \%, 95 \%$ CI: $76.2-86.0 \%)$. The mean age of the patients was 66 years; 133 were men $(54.5 \%)$. The rate of complete colonoscopy in patients with poor bowel preparation was $65.9 \%$ (95\% CI: $60.0-71.9 \%$ ) compared to 89.9\% (95\% CI: 86.1-93.7\%) in patients with good bowel preparation $(p<0.001)$. Incomplete colonoscopy due to poor bowel preparation added a total of 64 extra days of admission before performing repeat colonoscopy or CT-colonography, in 21 patients, representing a mean additional hospitalization duration of 3 days.
Overall, $40.2 \%$ of patients had previous abdominal surgery, $31.4 \%$ were diabetic, $29.5 \%$ had limited mobility, and $10.3 \%$ had a neurologic condition. The comorbid score was greater than or equal to 3 in half the patients. Medication history was also assessed; overall $37.4 \%$ of patients received more than 8 medications and $17.4 \%$ were on narcotics.

In univariable analyses, the only clinical variable associated with a poor bowel preparation was advancing age. The median age of the patients with poor bowel preparation was 76 versus 67 in patients with adequate preparation $(p<$ $0.001)$. Certain factors such as diabetes $(p=0.06)$, limited mobility $(p=0.075)$, and elevated comorbid score (CCI $\geq$ $3, p=0.068)$ trended towards significance (Table 1). Bowel preparation was most often achieved using a PEG solution preparation (88.9\%). Split preparation was only used in $9.9 \%$ of patients.

In multivariable logistic regression analyses, adjusting for gender, CCI, diabetes, and poor mobility, age remained independently and significantly predictive $(\mathrm{OR}=1.026$, CI: 1.006 to 1.045 , and $p=0.008$ ). The model obtained a VIF of 2.52 and a tolerance of 0.40 . Based on this, we calculated that, for every 10-year increase in age, the likelihood of poor bowel preparation increased by 1.29 (Table 2 ).

The predetermined sample size of 500 was not achieved during the study because of limitation in the study period.

\section{Discussion}

Colonoscopy is an important diagnostic and therapeutic tool to assess and treat patients hospitalized with gastrointestinal disease. Adequate colonic mucosa visualization is necessary for proper assessment and is related to the quality of bowel preparation [19-21]. Hospitalization status has been identified as a risk factor for poor bowel preparation, but the reason for this association is unclear $[5,6]$. Our study is the first to focus on predictors of poor bowel preparation specifically in hospitalized patients.

In this cohort, the rate of poor bowel preparation was $34.0 \%$ (95\% CI: $28.1-39.9 \%$ ), which is similar to previously published data where rates range from 17 to $38 \%[6,8,9,11,12$, $16,22-24]$. The rate of complete colonoscopy in patients with poor bowel preparation was $65.9 \%$ (95\% CI: $60.0-71.9 \%$ ). Overall, the rate of cecal intubation was 81.1\% (95\% CI: 76.2$86.0 \%$ ), which is comparable to previously published data in hospitalized patients, reporting a cecal intubation rate of $88 \%$ (95\% CI: 79-97\%) [25].

We identified that age was a key factor predicting poor bowel preparation in hospitalized patients. In uni- and multivariable analysis, age was the only significant predictor of poor preparation. Furthermore, for every 10 -year increase in age, the odds of having poor bowel preparation increased by 1.29. Age has been previously described as a predictor of poor bowel preparation $[3,5,8,11]$, but this is the first such report specifically in a hospitalized patient population.

The high rate of poor bowel preparation and subsequent lower cecal intubation rate may have been impacted by our cohort's comorbid status. Moreover, increasing comorbidities has been identified previously as causally related to inadequate bowel preparation in primary outpatient populations 
TABLE 1: Characteristics of patients as a function of bowel preparation.

\begin{tabular}{|c|c|c|c|c|}
\hline & Overall & Poor bowel preparation & Adequate bowel preparation & $p^{*}$ \\
\hline Number of patients (\%) & 244 & $85(34.8)$ & $158(64.8)$ & \\
\hline Median age $[\mathrm{IQR}]$ & $71[58,79]$ & $76[64.5,82]$ & $67[53,77]$ & $<0.001^{\mathrm{t}}$ \\
\hline \multicolumn{5}{|l|}{ Gender (\%) } \\
\hline Male & 54.7 & 52.9 & 55.7 & \multirow{2}{*}{0.688} \\
\hline Female & 45.3 & 47.1 & 44.3 & \\
\hline \multicolumn{5}{|l|}{ Comorbidity (\%) } \\
\hline Diabetes & 31.4 & 39.3 & 27.2 & 0.06 \\
\hline Neurologic condition & 10.3 & 14.6 & 6.5 & 0.296 \\
\hline Limited mobility & 29.5 & 36.9 & 25.5 & 0.075 \\
\hline Previous abdominal surgery & 40.2 & 34.6 & 43.2 & 0.253 \\
\hline \multicolumn{5}{|c|}{ Charlson Comorbidity Index (CCI) (\%) } \\
\hline 0 & 20.2 & 16.7 & 22.2 & \multirow{4}{*}{0.068} \\
\hline 1 & 12.8 & 8.3 & 15.2 & \\
\hline 2 & 16.5 & 13.1 & 18.4 & \\
\hline$\geq 3$ & 50.4 & 61.9 & 44.3 & \\
\hline \multicolumn{5}{|l|}{ Medication (Rx) (\%) } \\
\hline More than $8 \mathrm{Rx}$ & 37.4 & 42.4 & 35.0 & 0.270 \\
\hline Narcotic & 17.4 & 21.4 & 15.3 & 0.285 \\
\hline \multicolumn{5}{|c|}{ Bowel preparation and procedure (\%) } \\
\hline PEG with electrolytes & 88.9 & 87.7 & 89.5 & \multirow{2}{*}{0.466} \\
\hline Sodium picosulfate & 9.0 & 9.9 & 8.5 & \\
\hline Split dose & 9.9 & 11.2 & 9.2 & 0.648 \\
\hline Time of procedure $(\mathrm{PM})$ & 58.9 & 58.4 & 59.2 & 0.915 \\
\hline
\end{tabular}

${ }^{*}$ Chi-square association between patient characteristics and bowel preparation.

${ }^{\mathrm{t}}$ Mann-Whitney test performed.

TABLE 2: Multivariable analysis predicting poor bowel preparation.

\begin{tabular}{|c|c|c|}
\hline & OR (95\% CI) & $p^{*}$ \\
\hline Age & $1.03(1.01-1.05)$ & 0.016 \\
\hline \multicolumn{3}{|l|}{ Gender } \\
\hline Male & \multicolumn{2}{|c|}{ Ref. } \\
\hline Female & $1.34(0.76-2.36)$ & 0.310 \\
\hline \multicolumn{3}{|l|}{ CCI } \\
\hline 0 & \multicolumn{2}{|c|}{ Ref. } \\
\hline 1 & $0.46(0.15-1.43)$ & 0.177 \\
\hline 2 & $0.57(0.20-1.62)$ & 0.288 \\
\hline$\geq 3$ & $1.16(0.48-2.82)$ & 0.738 \\
\hline \multicolumn{3}{|l|}{ Comorbidity } \\
\hline Diabetes & $1.24(0.65-2.36)$ & 0.520 \\
\hline Poor mobility & $1.38(0.74-2.56)$ & 0.312 \\
\hline
\end{tabular}

${ }^{*}$ Multivariate logistic regression.

$[6,8,9,11]$. In our study, diabetes and elevated comorbid score trended towards statistical significance as predictors of inadequate preparation. Diabetes may contribute to poor bowel preparation because of associated autonomic neuropathy and subsequent constipation. Our study was underpowered and thus assessing a greater number of patients would be necessary to confirm that these factors are indeed significant predictors of poor bowel preparation.
Inpatient status has been identified as a predictor of poor bowel preparation $[5,23]$. Even with adequate preparation, completion rates of colonoscopies in inpatients have been documented to be lower than those of outpatients [23]. Comparative data from 1988 and 2008 have suggested that inpatient colonoscopies are currently being performed on markedly sicker patients [25]. Interestingly, cecal intubation rates have increased over time, owing largely to improved endoscopic techniques and technology [25]. It is unclear what the driving force behind inadequate bowel preparation is; however, it is likely that based on the available observational data in sicker patients adequate bowel preparation is harder to achieve.

Patients with poor bowel preparation stayed an average of 3 additional days in hospital. This raises concern of increased costs to the health care system. A study from 2002 documented that incomplete examinations were associated with a $12 \%$ and $22 \%$ increase in costs in private and public hospitals, respectively [13]. This highlights a significant burden to the health care systems, suggesting that measures should be taken to increase successful preparation. Although the observational and retrospective nature of our study shows an association (and does not ascertain for cause), one may advocate for an age-specific approach to inpatient bowel preparation, with attention given to elderly patients who may have difficulty completing their preparations, to avoid 
potentially unnecessary health care expenditures due to poor preparation among elderly hospitalized individuals.

The limitations of our study include its retrospective design, which can lead to bias, as well as being underpowered. It is possible that we did not observe any significant differences because of the inability to achieve the desired sample size. The lack of power may explain why other patientcentered factors, particularly comorbid status, were not significant in our data set. Preparation-based factors such as split-dose preparation and runway time could also have been affected by the lack of power thus leading to a type 2 error. Other possible reasons for not duplicating findings from other studies would include variations in patient characteristics, including language barriers, as well as nursing and medical practices. Moreover, bowel preparation was not standardized at our institution, which may represent an important confounder. On that matter, there are potentially other unmeasured confounders that may ascertain for our findings. For example, sicker patients were potentially unable to take the prep and had a longer hospital stay due to their multimorbidity.

In conclusion, $34.0 \%$ of inpatients had poor bowel preparation and the rate of complete colonoscopy in this group was $65.9 \%$ (95\% CI: 60.0-71.9\%). In uni- and multivariable analysis, age was the only independent significant predictor of poor bowel preparation. An age-specific approach should be implemented to minimize this factor in relation to poor bowel preparation. The broader use of split-dosing preparations may result in increased bowel cleanliness in this patient population, although high quality evidence in this difficult group is lacking at present.

\section{Additional Points}

At the authors' tertiary care referral center, poor bowel preparation is frequently reported $(34.0 \%)$ in the hospitalized settings. In the hospitalized patients, age is the only independent predictor of poor bowel preparation.

\section{Disclosure}

Julia McNabb-Baltar is the 2012 Canadian Association of Gastroenterology Takeda Resident Research Award winner.

\section{Competing Interests}

The authors declare that they have no competing interests.

\section{References}

[1] K. M. Lee, K. K. Saules, C. S. Pomerleau et al., "Evaluating the ability of visual images to inform college women about the link between smoking and cervical intraepithelial neoplasia (CIN) and to motivate quitting: critical dimensions," Journal of Cancer Education, vol. 22, no. 3, pp. 154-158, 2007.

[2] D. K. Rex, J. H. Bond, S. Winawer et al., "Quality in the technical performance of colonoscopy and the continuous quality improvement process for colonoscopy: recommendations of the
U.S. Multi-Society Task Force on Colorectal Cancer," American Journal of Gastroenterology, vol. 97, no. 6, pp. 1296-1308, 2002.

[3] M. Gupta, J. L. Holub, and G. Eisen, "Do indication and demographics for colonoscopy affect completion? A large national database evaluation," European Journal of Gastroenterology \& Hepatology, vol. 22, no. 5, pp. 620-627, 2010.

[4] M. R. Sanaka, N. Shah, K. D. Mullen, D. R. Ferguson, C. Thomas, and A. J. McCullough, "Afternoon colonoscopies have higher failure rates than morning colonoscopies," American Journal of Gastroenterology, vol. 101, no. 12, pp. 2726-2730, 2006.

[5] B. Lebwohl, T. C. Wang, and A. I. Neugut, "Socioeconomic and other predictors of colonoscopy preparation quality," Digestive Diseases and Sciences, vol. 55, no. 7, pp. 2014-2020, 2010.

[6] R. M. Ness, R. Manam, H. Hoen, and N. Chalasani, "Predictors of inadequate bowel preparation for colonoscopy," The American Journal of Gastroenterology, vol. 96, no. 6, pp. 1797-1802, 2001.

[7] E. H. Seo, T. O. Kim, M. J. Park et al., “Optimal preparationto-colonoscopy interval in split-dose PEG bowel preparation determines satisfactory bowel preparation quality: an observational prospective study," Gastrointestinal Endoscopy, vol. 75, no. 3, pp. 583-590, 2012.

[8] Y. W. Chung, D. S. Han, K. H. Park et al., "Patient factors predictive of inadequate bowel preparation using polyethylene glycol a prospective study in Korea," Journal of Clinical Gastroenterology, vol. 43, pp. 448-452, 2009.

[9] H. Fatima, C. S. Johnson, and D. K. Rex, "Patients' description of rectal effluent and quality of bowel preparation at colonoscopy," Gastrointestinal Endoscopy, vol. 71, no. 7, pp. 1244.e2-1252.e2, 2010.

[10] D. L. Nguyen and M. Wieland, "Risk factors predictive of poor quality preparation during average risk colonoscopy screening: the importance of health literacy," Journal of Gastrointestinal and Liver Diseases, vol. 19, no. 4, pp. 369-372, 2010.

[11] B. B. Borg, N. K. Gupta, G. R. Zuckerman, B. Banerjee, and C. P. Gyawali, "Impact of obesity on bowel preparation for colonoscopy," Clinical Gastroenterology and Hepatology, vol. 7, no. 6, pp. 670-675, 2009.

[12] W.-K. Chan, A. Saravanan, J. Manikam, K.-L. Goh, and S. Mahadeva, "Appointment waiting times and education level influence the quality of bowel preparation in adult patients undergoing colonoscopy," BMC Gastroenterology, vol. 11, article 86, 2011.

[13] D. K. Rex, T. F. Imperiale, D. R. Latinovich, and L. L. Bratcher, "Impact of bowel preparation on efficiency and cost of colonoscopy," American Journal of Gastroenterology, vol. 97, no. 7, pp. 1696-1700, 2002.

[14] R. A. Deyo, D. C. Cherkin, and M. A. Ciol, "Adapting a clinical comorbidity index for use with ICD-9-CM administrative databases," Journal of Clinical Epidemiology, vol. 45, no. 6, pp. 613-619, 1992.

[15] M. E. Charlson, F. L. Sax, C. R. MacKenzie, S. D. Fields, R. L. Braham, and R. G. Douglas Jr., "Assessing illness severity: does clinical judgment work?" Journal of Chronic Diseases, vol. 39, no. 6, pp. 439-452, 1986.

[16] G. C. Harewood, V. K. Sharma, and P. de Garmo, "Impact of colonoscopy preparation quality on detection of suspected colonic neoplasia," Gastrointestinal Endoscopy, vol. 58, no. 1, pp. 76-79, 2003.

[17] M. Mazumdar and J. R. Glassman, "Categorizing a prognostic variable: review of methods, code for easy implementation and applications to decision-making about cancer treatments," Statistics in Medicine, vol. 19, no. 1, pp. 113-132, 2000. 
[18] R. M. O’Brien, "A caution regarding rules of thumb for variance inflation factors," Quality \& Quantity, vol. 41, no. 5, pp. 673-690, 2007.

[19] R. Coriat, A. Lecler, D. Lamarque et al., "Quality indicators for colonoscopy procedures: a prospective multicentre method for endoscopy units," PLoS ONE, vol. 7, no. 4, Article ID e33957, 2012.

[20] J. Church, "Adenoma detection rate and the quality of colonoscopy: the sword has two edges," Diseases of the Colon \& Rectum, vol. 51, no. 5, pp. 520-523, 2008.

[21] S. D. Wexner, D. E. Beck, T. H. Baron et al., "A consensus document on bowel preparation before colonoscopy: prepared by a Task Force from the American Society of Colon and Rectal Surgeons (ASCRS), the American Society for Gastrointestinal Endoscopy (ASGE), and the society of American Gastrointestinal and Endoscopic Surgeons (SAGES) (vol 63, pg 894, 2006)," Gastrointestinal Endoscopy, vol. 64, p. 154, 2006.

[22] F. Froehlich, V. Wietlisbach, J.-J. Gonvers, B. Burnand, and J.-P. Vader, "Impact of colonic cleansing on quality and diagnostic yield of colonoscopy: the European Panel of Appropriateness of Gastrointestinal Endoscopy European multicenter study," Gastrointestinal Endoscopy, vol. 61, no. 3, pp. 378-384, 2005.

[23] P. O. Hendry, J. T. Jenkins, and R. H. Diament, “The impact of poor bowel preparation on colonoscopy: a prospective single centre study of 10571 colonoscopies," Colorectal Disease, vol. 9, no. 8, pp. 745-748, 2007.

[24] B. Lebwohl, F. Kastrinos, M. Glick, A. J. Rosenbaum, T. Wang, and A. I. Neugut, "The impact of suboptimal bowel preparation on adenoma miss rates and the factors associated with early repeat colonoscopy," Gastrointestinal Endoscopy, vol. 73, no. 6, pp. 1207-1214, 2011.

[25] M. S. Cappell and R. Abboud, "The impact of advances in instrumentation and techniques of colonoscopy from 1988 to 2008 on inpatient colonoscopy performance at a high volume endoscopy unit in the United States: significantly shorter procedure time, higher completion rate, performance on sicker inpatients, and near disappearance of flexible sigmoidoscopy," Digestive Diseases and Sciences, vol. 55, no. 12, pp. 3521-3529, 2010. 